\title{
Level of Blood Pressure above Goal and Clinical Inertia in a Medicaid Population
}

\author{
Anthony J. Viera, MD, MPH ${ }^{1}$, Dorothee Schmid, MA $^{2}$, Susan Bostrom, $\mathbf{R N}^{3}$, Angie Yow, \\ $\mathbf{R N}^{3}$, William Lawrence, $\mathbf{M D}^{3,4,5}$, and C. Annette DuBard, MD, $\mathbf{M P H}^{1,3,6}$ \\ ${ }^{1}$ Department of Family Medicine, University of North Carolina at Chapel Hill \\ ${ }^{2}$ North Carolina State Center for Health Statistics \\ ${ }^{3}$ North Carolina Division of Medical Assistance \\ ${ }^{4}$ Department of Pediatrics, University of North Carolina at Chapel Hill \\ ${ }^{5}$ Duke Primary Care, Duke University Health Systems \\ ${ }^{6}$ Cecil G. Sheps Center for Health Services Research, University of North Carolina at Chapel Hill
}

\begin{abstract}
Failure to adjust hypertension therapy despite elevated blood pressure (BP) levels is an important contributor to lack of BP control. One possible explanation is that small elevations above goal BP are not concerning to clinicians. BP levels farther above goal, however, should be more likely to prompt clinical action. We reviewed one year's worth of primary care records of 3,742 North Carolina Medicaid recipients 21 years and older with hypertension (a total of 15,516 office visits) to examine variations in hypertension management stratified by level of BP above goal and the association of BP level above goal with documented anti-hypertensive medication change. Among the $53 \%$ of patients not at goal BP, $42 \%$ were within $10 / 5 \mathrm{~mm} \mathrm{Hg}$ of goal; $11 \%$ had a BP $\geq 40 / 20$ $\mathrm{mm} \mathrm{Hg}$ above goal. Higher level of BP above goal was independently associated with antihypertensive medication change. Compared to visits at which BP was $<10 / 5 \mathrm{~mm} \mathrm{Hg}$ above goal, the adjusted odds of medication change were 7.9 (95\% CI 6.2-10.2) times greater at visits when patients' BP was $\geq 40 / 20 \mathrm{~mm} \mathrm{Hg}$ above goal. However, even when BP was above goal at this level, treatment change occurred only $46 \%$ (95\% CI 40.2-51.8) of the time.
\end{abstract}

\section{INTRODUCTION}

Lack of control of elevated blood pressure (BP) represents an important public health problem, responsible for considerable cardiovascular disease (CVD) morbidity and mortality. ${ }^{1}$ Among the modifiable factors known to be associated with poor BP control, suboptimal therapy is the most clinically important. ${ }^{2,3}$ In fact, most uncontrolled BP occurs not among people with poor access to care, but rather among patients with known

\footnotetext{
(C) 2010 American Society of Hypertension. Published by Elsevier Inc. All rights reserved.

Corresponding Author: Anthony J. Viera, MD, MPH Assistant Professor Department of Family Medicine University of North Carolina at Chapel Hill 590 Manning Drive, CB 7595 Chapel Hill, NC 27599 Phone (919) 966-0758 anthony_viera@ med.unc.edu. Conflicts on interest: Nothing to disclose

Financial disclosures: None

Publisher's Disclaimer: This is a PDF file of an unedited manuscript that has been accepted for publication. As a service to our customers we are providing this early version of the manuscript. The manuscript will undergo copyediting, typesetting, and review of the resulting proof before it is published in its final citable form. Please note that during the production process errors may be discovered which could affect the content, and all legal disclaimers that apply to the journal pertain.
} 
hypertension who have a usual source of care and who make regular clinic visits. ${ }^{4}$ The failure of clinicians to initiate or intensify antihypertensive therapy despite elevated BP levels has been termed clinical inertia ${ }^{5}$, and continued efforts are needed to overcome this major impediment to achieving BP control.

One hypertension clinical action model conceptualizes clinical inertia as stemming from four domains: organizational factors (e.g., sufficient support staff, access to follow-up), competing demands and prioritization (e.g., patients with several comorbidities or multiple complaints), medication related factors (e.g., number of medications, side effects), and clinical uncertainty. ${ }^{6}$ Clinical uncertainty reflects the fact that a clinic BP can be a poor gauge of a patient's true BP status.

The domain of clinical uncertainty perhaps best encapsulates many of the reasons clinicians use to avoid intensification of therapy or to explain but not act on an elevated clinic BP, including that the BP goal has almost been reached. ${ }^{5-7} \mathrm{BP}$ varies enough such that elevations within $5 \mathrm{~mm} \mathrm{Hg}$ or in some cases $10 \mathrm{~mm} \mathrm{Hg}$ above goal noted on a single visit might be viewed by clinicians in many instances as acceptable control, especially given that proper BP measurement technique is often not followed in clinical practice. In addition, clinicians may consider the commonness of the white-coat effect among treated hypertensives. ${ }^{8,9}$ The view that "close to goal is good enough" may be especially true during visits for other problems, particularly acute care visits unrelated to hypertension. However, higher elevations of BP are more likely to indicate that BP is truly uncontrolled, should be more concerning to clinicians, and therefore ought to prompt action by clinicians regardless of the type of visit, particularly if BP has been elevated on one or more previous visits.

Using a statewide sample of primary care clinicians providing hypertension management to Medicaid patients, we examined rates of BP control, hypertension management patterns, and degree of BP elevation for patients with above-goal BP. We then examined the relationship between degree of BP elevation above goal and documented changes in anti-hypertensive therapy over the course of one year's visits.

\section{METHODS}

\section{Population and Sampling}

Medicaid administrative data were used to select a representative sample of 3,742 NC Medicaid recipients age 21 and older with hypertension managed in the primary care setting. Recipients were enrolled with Medicaid for at least 11 months between July 1, 2005 and June 30, 2006, and had an office visit with a diagnosis of hypertension (ICD9 401xx), excluding pregnancy-induced hypertension. Patients who had any office visits with a cardiologist or endocrinologist during this time were excluded, as were those receiving dialysis services.

Primary care providers (PCPs) were identified according to Medicaid administrative data and from professional services claims by clinicians of the following specialties: general or family medicine, internal medicine, obstetrics/gynecology, and nurse practitioner. In Medicaid administrative data, "provider" may refer to a single physician or a practice organization. Therefore, the following practice types were also included in claims review for PCP: federally qualified health center, health department, and rural health clinic. The provider who had submitted the most claims (or the provider submitting the most recent claim in the case of a tie) was identified as that patient's PCP. Providers with fewer than five patients in the population were excluded. For purposes of a quality improvement initiative unrelated to this analysis, four sampling strata were used. Providers were selected at random 
from each of the four strata. Within randomly selected providers, all eligible charts were reviewed.

\section{Data Abstraction}

Charts were reviewed in the offices of the PCPs. Only a small proportion of the practices used an electronic medical record (EMR). Data from records were abstracted using an electronic clinical data entry tool. Michigan Peer Review Organization developed the abstraction tool in cooperation with NC Division of Medical Assistance (DMA). Coloradobased Q Mark Inc. built the electronic abstraction tool and provided trained nurses for the abstractions. A total of 4,046 charts were abstracted. Of these, 224 were excluded from analysis because no hypertension diagnosis was found in the chart, and 80 were excluded because no BP measurement was found subsequent to June 30, 2005. Data from charts of 3,742 patients seen by 160 PCPs were included in analysis. For visit-level analyses, detailed information from up to the five most recent office visits made by the sample patients within the preceding 12 months was abstracted.

\section{Variables}

Length of time with current PCP practice was calculated based on the earliest service date and the most recent service date documented in the chart. PCP specialty was determined by the self-identification of the billing practice as recorded in Medicaid administrative data. Patient race was recorded from the chart abstracted. If race was not documented in the chart, we used race as listed in the Medicaid Client Case files. The presence of other chronic medical conditions was based on documentation of the diagnoses in the medical record. For the variable "multiple chronic conditions", congestive heart failure, coronary artery disease, peripheral arterial disease and stroke/transient ischemic attack were all grouped as one condition (cardiovascular disease). Similarly, substance abuse, depression, anxiety, and other psychiatric disorders were counted as a single condition (mental illness); and chronic obstructive pulmonary disease and asthma were counted as a single condition (respiratory illness).

Study analyses were based on diagnoses, results, treatments and actions documented in the medical records. BP treatment goals were defined as $<130 / 80 \mathrm{~mm} \mathrm{Hg}$ for patients with diabetes, otherwise $<140 / 90 \mathrm{~mm} \mathrm{Hg}$, in accordance with JNC7 guidelines. ${ }^{10}$ Above-goal BP was categorized based on whichever measurement (systolic or diastolic) placed patient into higher category. For example, a person categorized as having BP $\geq 20 / 10 \mathrm{~mm} \mathrm{Hg}$ above goal means that either the systolic BP (SBP) was $\geq 20 \mathrm{~mm} \mathrm{Hg}$ above goal or the diastolic BP (DBP) was $\geq 10 \mathrm{~mm} \mathrm{Hg}$ above goal, or both. The most recent BP measurement noted in the chart was used to determine level of control in patient-level analyses. For visit-level analyses, provider response to elevated BP during the visit is based on information gathered from the chart, usually noted in the "assessment and plan" portion of a visit note. In order to attempt to account for visits at which a clinician might wait on further documented elevations of BP before changing therapy, we also created a covariate to reflect the number of prior visits during the study year at which BP was elevated. Provider responses to elevated BP were noted as change in antihypertensive medication regimen, any documented lifestyle recommendation, and/or plan for follow-up BP. We included provider responses of addressing adherence in the lifestyle recommendation category. Visits were categorized as chronic care visits or acute care/other visits based on the chief complaint or reason noted in the chart for the visit. In the abstraction tool, acute visits were defined as visits of an episodic nature with recently noted symptoms of a particular time frame (e.g., sore throat, back pain for one month). Chronic visits were defined as visits recorded for follow-up of an existing diagnosis (e.g., hypertension or diabetes), an annual physical exam, or a check such as blood pressure check, blood sugar check, medication check or review. 


\section{Analysis}

Data were analyzed using SAS version 9.2 (SAS Institute, Cary, North Carolina). Weights were applied to reflect the unequal chance of being selected for providers in the different strata (which were otherwise unrelated to this analysis). The 95\% confidence intervals are based on the weighted frequencies. For significance testing, the F-adjusted Rao-Scott chi square test was used. After completing patient-level analyses to examine BP control rates and general hypertension management, we conducted visit-level analyses to examine the relationship of BP level above goal with documented changes in BP medication during that office visit. We also examined the associations of several potential covariates with documented BP medication changes. Bivariate relationships were tested using F-adjusted Rao-Scott chi square. Variables associated at a p-value $<0.10$ with documented changes in medication were placed into a multivariable logistic regression model to estimate their independent contributions. Key variables of interest (sex and race) were retained in the model.

This study was performed as part of a quality improvement activity of the NC DMA, and exempted for review by the University of North Carolina Office of Human Research Ethics.

\section{RESULTS}

\section{Characteristics of Patients in Analysis}

A total of 3,742 patient charts were reviewed. Nearly $71 \%$ of patients were female (Table 1), a proportion that is close to the $72 \%$ of adults eligible for Medicaid in North Carolina. Most patients were $\geq 40$ years, and approximately $52 \%$ of the patients were Black. Approximately $44 \%$ were current smokers. Obesity $(60 \%)$ and diabetes (39\%) were common, as was mental illness or substance abuse (35\%) and chronic pain (31\%). Approximately 55\% of patients visited a family physician or general practitioner for their primary care; $30 \%$ visited an internist. Approximately $90 \%$ of patients had continuity of care of at least one year with their PCP, and almost $40 \%$ had continuity of care of five years or more.

\section{Patient-Level Blood Pressure Control}

Overall, BP was at goal in 47\% (95\% CI 44.6-49.7) of patients. BP was more than twice as likely to be at goal among nondiabetics $(60 \%$ vs $27 \%, \mathrm{p}<0.0001)$ (Figure 1). Among the $53 \%$ of patients whose office BP was not at goal, $42 \%$ were within $10 / 5 \mathrm{~mm} \mathrm{Hg}$ of their goal BP (Table 2). Approximately $22 \%$ of patients whose BP was not at goal had a SBP 10-19 $\mathrm{mm} \mathrm{Hg}$ or a DBP 5-9 mm Hg above goal; $18 \%$ had a SBP 20-29 mm Hg or DBP 10-14 mm $\mathrm{Hg}$ above goal; $7 \%$ had a SBP $30-39 \mathrm{~mm} \mathrm{Hg}$ or DBP $15-19 \mathrm{~mm} \mathrm{Hg}$ above goal; and $11 \%$ had a SBP $\geq 40 \mathrm{~mm} \mathrm{Hg}$ or DBP $\geq 20 \mathrm{~mm} \mathrm{Hg}$ above goal. In addition to being more likely to have BP not at goal, diabetics were also more likely to have BP more than $20 / 10 \mathrm{~mm} \mathrm{Hg}$ above goal ( $28 \%$ vs $14 \%$, p $<0.0001)$ (Figure 1$)$.

Among patients whose most recent BP was above goal, 36\% (95\% CI 32.3-40.4) had elevation of SBP only, 17\% (95\% CI 14.2-20.7) had elevation of DBP only, and 46\% (95\% CI 43.2-49.2) had elevations in both systolic and diastolic BP. Worth noting also is that $86 \%$ (95\% CI 83.5-88.0) of subjects with BP above goal at the most recent visit also had BP above goal on at least one prior visit during the year, and 66\% (95\% CI 63.1-69.1) had a BP above goal on at least two prior visits.

\section{Documented Hypertension Management}

Approximately $44 \%$ of the patients had documentation of lifestyle counseling over the course of the preceding year (Table 3 ). The most commonly documented lifestyle modifications were diet (28\%) and exercise (21\%). Weight reduction was documented as 
addressed in $14 \%$, medication adherence in $11 \%$, and sodium restriction in $9.3 \%$. When comparing the lifestyle modifications addressed stratified by level of BP control, the most notable trend was in discussions of medication adherence. Such discussions were documented for $6.9 \%$ of patients whose BP was at goal compared to $19 \%$ of those whose BP was $\geq 20 / 10 \mathrm{~mm} \mathrm{Hg}$ above goal.

Approximately $93 \%$ of the patients in this sample were on one or more antihypertensive medications (Table 3 ). The most commonly prescribed drug classes were angiotensin converting enzyme (ACE)-inhibitors (40\%) and thiazide diuretics (40\%). Calcium channel blockers were prescribed for $31 \%$ and beta-blockers for $30 \%$. Among patients with BP at goal, $21 \%$ were prescribed three drug classes, and $14 \%$ were prescribed four or more drug classes.

During the study period, the sample patients made 15,516 clinic visits for which BP level above goal could be determined. Similar to the proportion of patients whose BP was uncontrolled at their most recent visit, BP was above goal at $54 \%$, or a total of 8228 , of all examined visits (Table 4). During visits ( $\mathrm{n}=3321)$ when SBP was $<10 \mathrm{~mm} \mathrm{Hg}$ above goal or DBP was $<5 \mathrm{~mm} \mathrm{Hg}$ above goal, at least one lifestyle recommendation (including addressing adherence) was documented in $14 \%$. During visits $(\mathrm{n}=1888)$ when SBP was 10-19 mm Hg above goal or DBP was 5-9 $\mathrm{mm} \mathrm{Hg}$ above goal, a lifestyle recommendation (including addressing adherence) was noted in $15 \%$. Among visits $(\mathrm{n}=981)$ with a documented SBP $\geq 40 \mathrm{~mm} \mathrm{Hg}$ or DBP $\geq 20 \mathrm{~mm} \mathrm{Hg}$ above goal, a lifestyle recommendation (including addressing adherence) was documented in $20 \%$.

At incrementally higher BP levels above goal, the proportion of visits at which patients received a request for closer follow-up was greater. Among patient visits $(\mathrm{n}=981)$ with a SBP $\geq 40 \mathrm{~mm} \mathrm{Hg}$ or DBP $\geq 20 \mathrm{~mm} \mathrm{Hg}$ above goal, $30 \%$ of patients were asked to follow-up within two to four weeks and $11 \%$ within two weeks. Still, even with this degree of BP elevation above goal, no follow-up plan was noted in $41 \%$ and no intervention or plan for close follow-up was noted in $30 \%$ of such visits (data not shown).

Hypertension management and treatment adjustments were significantly different between chronic care visits and acute/other care visits (Figure 2). For example, when SBP was 10-19 $\mathrm{mm} \mathrm{Hg}$ above goal or DBP was 5-9 $\mathrm{mm} \mathrm{Hg}$ above goal, a change in anti-hypertensive medication regimen was noted in $16.2 \%$ of chronic care visits compared to $5.7 \%$ of acute/ other care visits ( $\mathrm{p}<0.0001$ ). At visits when BP was $\geq 40 / 20 \mathrm{~mm} \mathrm{Hg}$ above goal, a change in anti-hypertensive medication regimen was noted in $49 \%$ of chronic care visits compared to $32 \%$ of acute/other care visits $(\mathrm{p}=0.0006)$. Among these same visits, no BP follow-up plan was noted in $36 \%$ of chronic care visits compared to $60 \%$ of acute/other visits.

\section{Anti-hypertensive Medication Changes at Visits when BP Levels were Above Goal}

Over the course of the patients' 8,238 visits, a medication change was documented for 1,717 (weighted percent, 21.1\%). In bivariate analyses, there was a clear direct relationship between higher levels of BP elevation above goal and documented change in antihypertensive medication regimen (Table 5). For example, among visits when the patient's BP level was $<10 / 5 \mathrm{~mm} \mathrm{Hg}$ above goal ( $\mathrm{n}=3321), 11 \%$ had a documented medication change, but among visits ( $\mathrm{n}=981)$ when BP was $\geq 40 / 20 \mathrm{~mm} \mathrm{Hg}$ above goal, $46 \%$ had a documented medication change. Other factors associated with a documented change in BP medication regimen were younger age group, non-obese BMI, not having diabetes, fewer chronic conditions, higher number of prior visits with above goal BP, and chronic care visit. Of note, sex, race, current tobacco use, time with PCP, and PCP specialty were not associated with documented change in BP medication regimen. 
To further examine the effect of preceding visits on medication changes, we also compared the percent of visits at which a medication change was documented when preceded by one or two visits at which $\mathrm{BP}$ was elevated. Among visits $(\mathrm{n}=6,123)$ preceded by one visit with a BP above goal, $14 \%$ had no documented BP medication change, and $23 \%$ had a documented medication change. Among visits $(n=4,193)$ preceded by two visits with $B P$ above goal, $15 \%$ had no documented BP medication change, and $22 \%$ had a documented medication change. Thus, while the percentage with a medication change was 1.5 times greater among those with a preceding visit with an above goal BP compared to those with no preceding visit above goal $(\mathrm{p}<0.0001)$, whether there was one preceding visit or two preceding visits with an elevated BP made little difference.

In multivariable analysis, the factors associated with a documented change in antihypertensive medication regimen were higher BP level above goal, younger age group, not having diabetes, and chronic care visit (Table 6). Compared to a visit when BP was $<10 / 5$ $\mathrm{mm} \mathrm{Hg}$ above goal, visits at which BP was $\geq 40 / 20 \mathrm{~mm} \mathrm{Hg}$ above goal had 7.9 times the odds of having a change in BP medication documented. Compared to BP-above-goal visits among patients $\geq 65$ years old, visits among patients 21-39 years of age had 1.8 times the odds of having a BP medication change. BP-above-goal visits among patients who did not have diabetes had nearly twice the odds of having a BP medication change documented. Compared to acute care visits, chronic care visits at which BP was above goal had over twice the odds of having a BP medication change documented. Number of prior visits above goal and having multiple chronic conditions were no longer significant when controlling for other effects.

\section{DISCUSSION}

Overall, we found BP to be controlled in approximately half of Medicaid patients in NC with documented hypertension, and that much uncontrolled BP is within $10 / 5 \mathrm{~mm} \mathrm{Hg}$ of goal clinic BP. Over $1 / 3$ of the patients with BP above goal in this sample had BP elevations at least $20 \mathrm{~mm} \mathrm{Hg}$ systolic or $10 \mathrm{~mm} \mathrm{Hg}$ diastolic, levels that more than double the risk of CVD complications. ${ }^{11}$ Existing therapeutic options have not been optimally utilized for these: half were prescribed two or fewer antihypertensive drug classes, and only half had any documented discussion of lifestyle recommendations or medication adherence during the prior year. Despite multiple visits with elevated BP readings during the course of a year, clinicians did not adjust therapy the majority of the time.

Not surprisingly, providers were more likely to change therapy at progressively higher levels of clinic BP. However, a concerning point is that even among patients for whom the SBP measurement was more than $40 \mathrm{~mm} \mathrm{Hg}$ above goal, therapy was adjusted only half the time. One could argue that with such extreme elevations, the clinician can be much more certain that the patient's BP is truly elevated and that the elevation cannot be "explained away". However, some degree of clinical inertia appears to be present even in the face of this nearcertainty. Therefore, other factors must play a role, and our study sheds some light on these as well.

We found that uncontrolled BP was more often addressed by medication change at chronic care visits than acute care visits, a relationship that was maintained after adjusting for other factors. However, the association of change in medication with having fewer chronic conditions was mitigated after adjusting for other factors (including type of visit). Another recent study found that patients who had comorbidities unrelated to hypertension were less likely to have uncontrolled hypertension addressed during a clinic visit. ${ }^{12}$ However, an important distinction to make is that the conditions were unrelated to hypertension (such as asthma, arthritis and gastroesophageal reflux), so would not include conditions such as heart 
disease and diabetes. Taken together, however, these findings still suggest that competing demands unfortunately often trump hypertension management.

Among patients in our study sample with above-goal BP, over one-quarter were on monotherapy, and a majority remained on fewer than three agents even at BP levels far above goal. Clinicians may overestimate the BP-lowering effect achievable with any single $\mathrm{BP}$ agent and may under-appreciate the fact, as demonstrated by clinical trials, that most patients will need more than one class of antihypertensive drug to reach target BP, and many patients will need at least three. ${ }^{13,14}$

We found that older patients were less likely to have their antihypertensive medication adjusted. One possible explanation is that clinicians may underestimate the benefit of BP control in older patients. It is also possible that clinicians view older age itself as a relative contraindication to more aggressive $\mathrm{BP}$ control, or that concerns over reducing diastolic BP too far limit clinicians' willingness to up-titrate BP medications. However, while some discretion must be used in lowering the diastolic BP below approximately $70 \mathrm{~mm} \mathrm{Hg}$ in patients with coronary artery disease, neither reason appears justified for most older patients. ${ }^{15,16} \mathrm{We}$ also found that diabetic patients were less likely to have BP medication adjusted when their BP was above goal. Clinicians may not realize the importance of BP control in diabetes, may accept lower degrees of control than recommended by national guidelines, or perhaps spend more effort on achieving glycemic control. ${ }^{10,13-17-19}$

A strength of this study is that the sample is representative of a statewide Medicaid provider population. It is worth noting that the patients in this study population are generally at higher risk for CVD events and poor health outcomes by virtue of their lower socioeconomic status and high prevalence of concomitant risk factors including diabetes and tobacco use. ${ }^{20}$

Therefore the difference between the actual care the patients are receiving and the improved or ideal care they could receive is substantial in terms of avoidable CVD morbidity, mortality, and health care costs, even in the short-term. Our estimates of BP control in this population may actually be overestimates because patients with more complicated disease (those seeing cardiologists and endocrinologists, those on dialysis) were excluded.

A limitation of this study is that our estimates of patient-level BP control are based on one visit's BP measurement(s), and the quality of the measurements (i.e., whether they were conducted according to recommendations) are unknown. However, BPs at more than $80 \%$ of the immediately preceding visits were also elevated. It is unlikely that alternative measures of BP control would have altered our conclusions. It has been shown that the use of the simplest approach, "last BP measurement recorded", yields results similar to the use of a threshold percent of visits with BP under control, or mean BP over time, for describing BP control in a population. ${ }^{21} \mathrm{~A}$ further reason for considering control rates based on one visit is that BP control as measured in quality measurement programs such as the National Committee for Quality Assurance is based on the most recent clinic BP reading during the measurement year. ${ }^{22}$

Our outcomes were based solely on chart documentation, so lifestyle recommendations and discussions of medication adherence may have been under-estimated if not documented. However, our main outcome of interest (BP medication change) should have been appropriately documented in the medical record, and we therefore would have captured it. We also acknowledge that BP medication change would not always mean intensification of therapy.

However, alternative reasons for making a medication change (such as poor tolerability, side effects or cost) would still be valid ways to address above-goal BP (because nonadherence is 
implied). We were unable to explore the degree to which provider uncertainty about patient adherence to the prescribed medical regimen was associated with BP medication change, or lack thereof.

The extent to which our findings are generalizable outside the Medicaid population is uncertain, though overall rates of BP control in our study population were similar to mean BP control rates reported by commercial health plans and Medicaid managed care organizations nationally. ${ }^{23}$ Another consideration is that we included only patients with diagnosed hypertension, and did not examine the proportion of Medicaid patients whose BP is elevated but for whom hypertension remains undiagnosed (and therefore uncontrolled).

Regardless, our findings suggest ample opportunity for improving hypertension management in the primary care setting. We are cognizant, however, that for Medicaid recipients and others with multiple complex health care needs, treatment objectives may not be achievable within predominant models of primary care practice. ${ }^{24}$ Hypertension management approaches that involve non-physician personnel in team-based care and offer patient self-management support and therapy intensification at more frequent intervals than the traditional physician-patient encounter have proven to be some of the most effective, ${ }^{25,26}$ but such approaches remain uncommon and may require substantial practice redesign and payment reform for spread and sustainability.

\section{Acknowledgments}

The authors would like to thank Marcus Plescia, MD, MPH, and Sara Huston, PhD, for their early contributions to this project, as well as participants in the UNC Chapel Hill K30 Clinical Research Curriculum for their review of a draft of the manuscript. An abstract of this work was presented at the 2010 meeting of the American Society of Hypertension.

Funding/support: Dr. Viera's time to develop this article was supported by a career development award from the National Institutes of Health (KL2RR025746).

\section{REFERENCES}

1. Gu Q, Burt VL, Paulose-Ram R, Yoon S, Gillum RF. High blood pressure and cardiovascular disease mortality risk among U.S. adults: the Third National Health and Nutrition Examination Survey Mortality Follow-up Study. Ann Epidemiol. 2008; 18:302-9. [PubMed: 18261929]

2. Berlowitz DR, Ash AS, Hickey EC, Friedman RH, Glickman M, Kader B, Moskowitz MA. Inadequate management of blood pressure in a hypertensive population. N Engl J Med. 1998; 339:1957-1963. [PubMed: 9869666]

3. Hyman DJ, Pavlik VN. Poor hypertension control: let's stop blaming the patients. Cleve Clin J Med. 2002; 69:793-799. [PubMed: 12371802]

4. Hyman DJ, Pavlik VN. Characteristics of patients with uncontrolled hypertension in the United States. N Engl J Med. 2001; 345:479-486. [PubMed: 11519501]

5. Phillips LS, Branch WT, Cook CB. Clinical inertia. Ann Intern Med. 2001; 135:825-834. [PubMed: 11694107]

6. Kerr EA, Zikmund-Fisher BJ, Klamerus ML, Subramanian U, Hogan MM, Hofer TP. The role of clinical uncertainty in treatment decisions for diabetic patients with uncontrolled blood pressure. Ann Intern Med. 2008; 148:717-727. [PubMed: 18490685]

7. Ferrari P, Hess L, Pechere-Bertschi A, Muggli F, Burnier M. Reasons for not intensifying antihypertensive treatment (RIAT): a primary care antihypertensive intervention study. J Hypertens. 2004; 22:1221-1229. [PubMed: 15167458]

8. MacDonald MB, Laing GP, Wilson MP, Wilson TW. Prevalence and predictors of white-coat response in patients with treated hypertension. CMAJ. 1999; 161:265-269. [PubMed: 10463047]

9. Myers MG, Oh PI, Reeves RA, Joyner CD. Prevalence of white coat effect in treated hypertensive patients in the community. Am J Hypertens. 1995; 8:591-597. [PubMed: 7662244] 
10. Chobanian AV, Bakris GL, Black HR, Cushman WC, Green LA, Izzo JL, et al. The Seventh Report of the Joint National Committee on Prevention, Detection, Evaluation, and Treatment of High Blood Pressure: the JNC 7 report. JAMA. 2003; 289:2560-2572. [PubMed: 12748199]

11. Lewington S, Clarke R, Qizilbash N, Peto R, Collins R, Prospective Studies Collaboration. Agespecific relevance of usual blood pressure to vascular mortality: a meta-analysis of individual data for one million adults in 61 prospective studies. Lancet. 2002; 360(9349):1903-13. [PubMed: 12493255]

12. Turner BJ, Hollenbeak CS, Weiner M, Ten Have T, Tang SS. Effect of unrelated comorbid conditions on hypertension management. Ann Intern Med. 2008; 148:578-586. [PubMed: 18413619]

13. Tight blood pressure control and risk of macrovascular and microvascular complications in type 2 diabetes: UKPDS 38. UK Prospective Diabetes Study Group. BMJ. 1998; 317:703-713. [PubMed: 9732337]

14. The ALLHAT Officers and Coordinators for the ALLHAT Collaborative Research Group. Major outcomes in high-risk hypertensive patients randomized to angiotensin-converting enzyme inhibitor or calcium channel blocker vs diuretic: the Antihypertensive and Lipid-Lowering Treatment to Prevent Heart Attack Trial (ALLHAT). JAMA. 2002; 288:2981-2997. [PubMed: 12479763]

15. Beckett NS, Peters R, Fletcher AE, et al. HYVET Study Group. Treatment of hypertension in patients 80 years of age or older. N Engl J Med. 2008; 358(18):1887-98. [PubMed: 18378519]

16. Fagard RH, Staessen JA, Thijs L, Celis H, Bulpitt CJ, de Leeuw PW, Leonetti G, Tuomilehto J, Yodfat Y. On-treatment diastolic blood pressure and prognosis in systolic hypertension. Arch Intern Med. 2007; 167(17):1884-91. [PubMed: 17893310]

17. Patel A, MacMahon S, Chalmers J, et al. Effects of a fixed combination of perindopril and indapamide on macrovascular and microvascular outcomes in patients with type 2 diabetes mellitus (the ADVANCE trial): a randomized controlled trial. Lancet. 2007; 370:829-840. [PubMed: 17765963]

18. Hansson L, Zanchetti A, Carruthers SG, et al. for the HOT Study Group. Effects of intensive blood-pressure lowering and low-dose aspirin in patients with hypertension: principal results of the Hypertension Optimal Treatment (HOT) randomized trial. Lancet. 1998; 351:1755-1762. [PubMed: 9635947]

19. Schrier RW, Estacio RO, Esler A, Mehler P. Effects of aggressive blood pressure control in normotensive type 2 diabetic patients on albuminuria, retinopathy and strokes. Kidney Int. 2002; 61:1086-97. [PubMed: 11849464]

20. Mensah GA, Mokdad AH, Ford ES, Greenlund KJ, Croft JB. State of disparities in cardiovascular health in the United States. Circulation. 2005; 111:1233-1241. [PubMed: 15769763]

21. Alexander M, Tekawa I, Hunkeler E, Fireman B, Rowell R, Selby JV, et al. Evaluating hypertension control in a managed care setting. Arch Intern Med. 1999; 159:2673-7. [PubMed: 10597757]

22. National Committee for Quality Assurance (NCQA) website. Available at: http://www.ncqa.org/tabid/59/Default.aspx.

23. The State of Health Care Quality. National Committee for Quality Assurance; Washington, D.C: 2009. http://www.ncqa.org/Portals/0/Newsroom/SOHC/SOHC_2009.pdf. Available at:

24. Østbye T, Yarnall KS, Krause KM, Pollak KI, Gradison M, Michener JL. Is there time for management of patients with chronic diseases in primary care? Ann Fam Med. 2005; 3(3):209-14. [PubMed: 15928223]

25. Green BB, Cook AJ, Ralston JD, Fishman PA, Catz SL, Carlson J, Carrell D, Tyll L, Larson EB, Thompson RS. Effectiveness of home blood pressure monitoring, web communication, and pharmacist care on hypertension control: a randomized controlled trial. JAMA. 2008; 299:2857_ 2867. [PubMed: 18577730]

26. Walsh JM, McDonald KM, Shojania KG, Sundaram V, Nayak S, Lewis R, Owens DK, Goldstein MK. Quality improvement strategies for hypertension management: a systematic review. Med Care. 2006; 44:646-657. [PubMed: 16799359] 


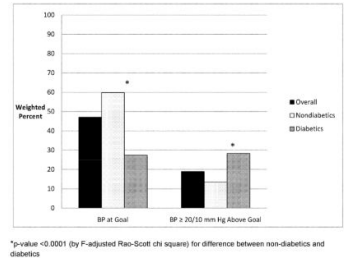

Figure 1.

Blood Pressure at Goal and Uncontrolled $\geq 20 / 10 \mathrm{~mm} \mathrm{Hg}$ above Goal, Overall and Stratified by Diabetes Status 


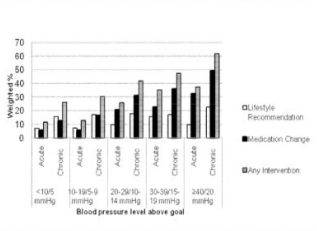

Figure 2.

Weighted Percent of Acute $(n=1376)$ and Chronic Care Visits $(n=6852)$ at which a Hypertension Management Intervention was Documented 
Table 1

Description of the Patients in the Study $(\mathrm{N}=3,742)$

\begin{tabular}{|c|c|c|c|}
\hline & $\mathbf{N}$ & $\begin{array}{l}\text { Weighted } \\
\text { Percent }\end{array}$ & $\begin{array}{r}95 \text { Confidence } \\
\text { Interval }\end{array}$ \\
\hline \multicolumn{4}{|l|}{ Patient Characteristics* } \\
\hline \multicolumn{4}{|l|}{ Sex } \\
\hline Male & 1,067 & 29.3 & $27.3-31.3$ \\
\hline Female & 2,675 & 70.7 & $68.7-72.7$ \\
\hline \multicolumn{4}{|l|}{ Age Groups } \\
\hline $21-39$ years & 628 & 16.6 & $14.5-18.7$ \\
\hline 40-64 years & 2,354 & 63.0 & $60.7-65.3$ \\
\hline 65 years and over & 760 & 20.4 & $17.6-23.3$ \\
\hline \multicolumn{4}{|l|}{ Race Groups } \\
\hline White & 1,436 & 42.7 & $34.7-50.8$ \\
\hline Black & 2,078 & 51.7 & $44.2-59.1$ \\
\hline Other or Unreported & 228 & 5.6 & $4.0-7.2$ \\
\hline Obesity (calculated BMI $\geq 30 \mathrm{~kg} / \mathrm{m}^{2}$ ) & 2,250 & 60.4 & $58.2-62.5$ \\
\hline \multicolumn{4}{|l|}{ Diagnosed Comorbidities } \\
\hline Diabetes & 1,435 & 39.2 & $37.2-41.2$ \\
\hline Hyperlipidemia & 1,622 & 44.4 & $41.5-47.3$ \\
\hline Coronary artery disease & 347 & 9.7 & $8.0-11.4$ \\
\hline Congestive heart failure & 200 & 5.8 & $4.5-7.0$ \\
\hline COPD or asthma & 724 & 19.8 & $17.8-21.8$ \\
\hline Stroke or TIA & 198 & 4.9 & $3.9-5.9$ \\
\hline Peripheral artery disease & 64 & 1.6 & $1.1-2.2$ \\
\hline Mental illness or substance abuse & 1,292 & 35.1 & $32.0-38.3$ \\
\hline Sleep apnea & 142 & 4.0 & $3.0-5.0$ \\
\hline Chronic pain & 1,159 & 30.5 & $27.1-33.8$ \\
\hline Current Tobacco use & 1,165 & 44.3 & $40.3-48.3$ \\
\hline \multicolumn{4}{|l|}{ Multiple chronic conditions ${ }^{\dagger}$} \\
\hline $0-1$ & 2,111 & 55.4 & $52.7-58.1$ \\
\hline $2-3$ & 1,532 & 41.9 & $39.3-44.5$ \\
\hline 4 or more & 99 & 2.7 & $2.0-3.4$ \\
\hline \multicolumn{4}{|l|}{ Length of time with current $\mathrm{PCP}^{\#}$} \\
\hline Less than 1 year & 349 & 8.4 & $6.8-10.0$ \\
\hline $1-2$ years & 1,268 & 32.4 & $27.4-37.4$ \\
\hline $3-4$ years & 677 & 19.5 & $16.6-22.4$ \\
\hline 5 or more years & 1,332 & 39.8 & $34.2-45.4$ \\
\hline \multicolumn{4}{|l|}{ PCP specialty } \\
\hline General/Family Practice & 1,944 & 54.9 & $40.6-69.2$ \\
\hline Internal Medicine & 1,391 & 30.4 & $17.6-43.3$ \\
\hline Other/Unknown & 407 & 14.7 & $5.9-23.5$ \\
\hline
\end{tabular}

$J$ Am Soc Hypertens. Author manuscript; available in PMC 2011 September 1. 
${ }^{\dagger}$ Chronic conditions include: diabetes, CVD (congestive heart failure, coronary artery disease, peripheral arterial disease, stroke, transient ischemic attack), mental illness, chronic pain, chronic obstructive pulmonary disease/asthma.

\# For 116 patients, no first visit date was abstracted. Therefore, care period length with their provider could not be established.

$* *$

Weighted Percent may not add up to 100 due to rounding.

Obesity prevalence estimate based on 3,663 patients with weight available. Abstracted height was used to calculate BMI for 2,124 patients. If height was unavailable, gender specific median height of the study population was applied. 
Table 2

Degree of Blood Pressure Elevation among Patients with Uncontrolled Blood Pressure* $(n=1,960)$

\begin{tabular}{lccc}
\hline & n & $\begin{array}{c}\text { Weighted } \\
\text { Percent }\end{array}$ & $\begin{array}{c}\text { 95\% Confidence } \\
\text { Interval }\end{array}$ \\
\hline$<10 / 5 \mathrm{~mm} \mathrm{Hg}$ above goal & 809 & 42.0 & $39.2-44.8$ \\
$10-19 / 5-9 \mathrm{~mm} \mathrm{Hg}$ above goal & 446 & 21.6 & $19.1-24.1$ \\
$20-29 / 10-14 \mathrm{~mm}$ Hg above goal & 349 & 18.2 & $16.5-20.0$ \\
$30-39 / 15-19 \mathrm{~mm}$ Hg above goal & 134 & 7.0 & $5.4-8.6$ \\
$\geq$ 40/20 mm Hg above goal & 222 & 11.2 & $9.6-12.8$ \\
\hline * & &
\end{tabular}

For example, a non-diabetic patient with a BP of 152/81 mm Hg would be placed in the category of BP 10-19/5-9 mm Hg above goal 


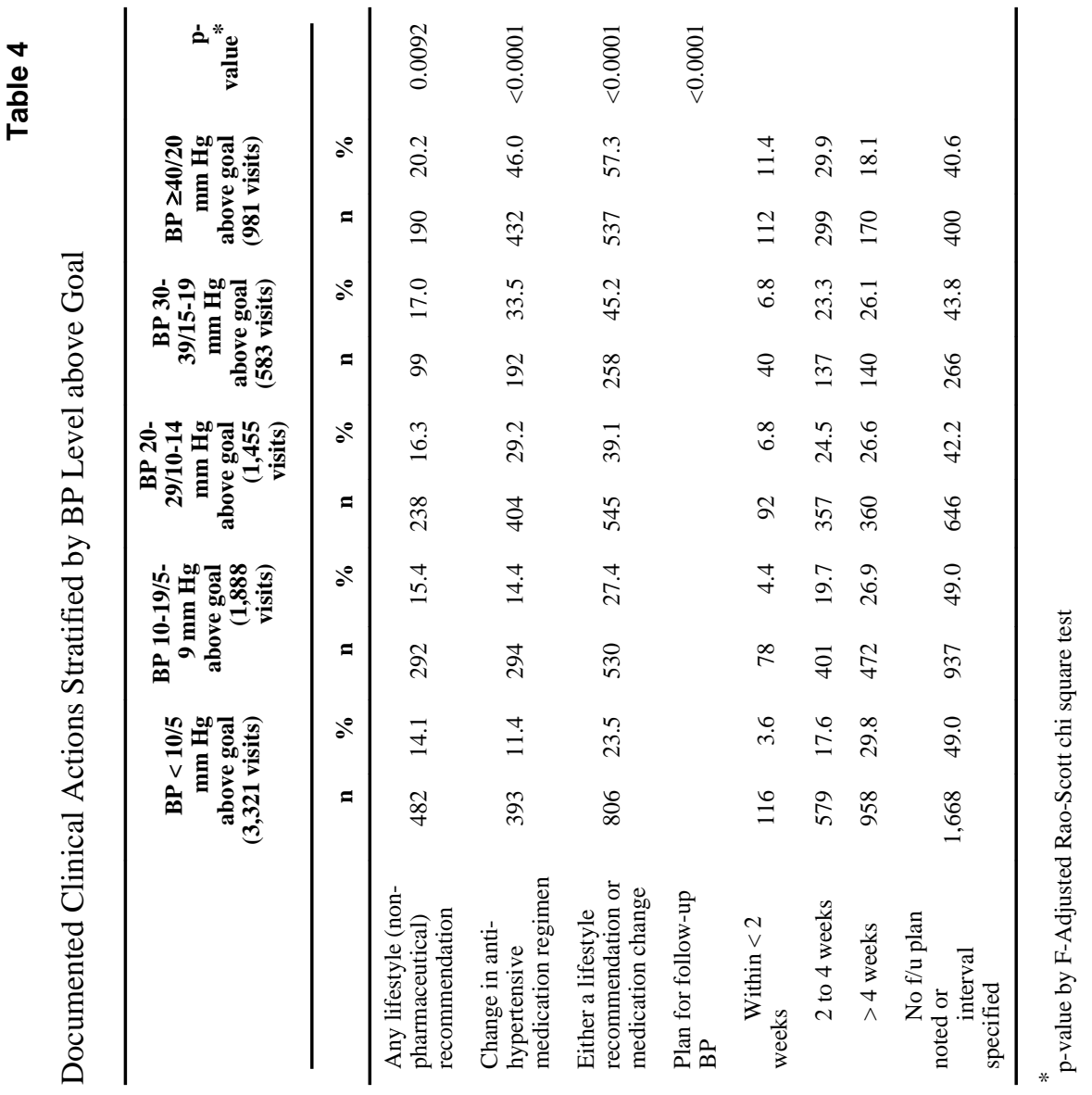


Table 5

Unadjusted Associations between Patient Characteristics and Documented Change in Anti-Hypertensive Medication(s) During Visits at Which Blood Pressure was Above Goal Over the Course of One Year $(\mathrm{n}=8,238)$

\begin{tabular}{|c|c|c|c|}
\hline Characteristic & $\mathbf{N}$ & Weighted \% & P-Value ${ }^{t}$ \\
\hline Total visits with medication change & 1,717 & 21.1 & \\
\hline BP level above goal* & & & $<0.0001$ \\
\hline$<10 / 5 \mathrm{~mm} \mathrm{Hg}$ & 393 & 11.4 & \\
\hline 10-19/5-9 mm Hg & 294 & 14.4 & \\
\hline 20-29/10-14 mm Hg & 404 & 29.2 & \\
\hline 30-39/15-19 mm Hg & 192 & 33.5 & \\
\hline$\geq 40 / 20 \mathrm{~mm} \mathrm{Hg}$ & 432 & 46.0 & \\
\hline Sex & & & 0.316 \\
\hline Male & 478 & 22.1 & \\
\hline Female & 1,239 & 20.7 & \\
\hline Age group & & & 0.0002 \\
\hline 21-39 years & 317 & 27.4 & \\
\hline 40-64 years & 1,071 & 20.6 & \\
\hline$\geq 65$ years & 329 & 18.4 & \\
\hline Race group & & & 0.239 \\
\hline White & 553 & 19.4 & \\
\hline Black & 1,064 & 22.3 & \\
\hline Other & 100 & 21.7 & \\
\hline Obesity & & & 0.020 \\
\hline $\mathrm{BMI}<30.0 \mathrm{~kg} / \mathrm{m} 2$ & 624 & 23.5 & \\
\hline Obese & 1,071 & 19.9 & \\
\hline BMI Unknown & 22 & 18.2 & \\
\hline Current Tobacco Use ${ }^{* *}$ & & & 0.250 \\
\hline No & 682 & 21.6 & \\
\hline Yes & 552 & 23.5 & \\
\hline Diabetes & & & $<0.0001$ \\
\hline No & 966 & 25.5 & \\
\hline Yes & 751 & 17.4 & \\
\hline Multiple chronic conditions & & & $<0.0001$ \\
\hline $0-1$ & 984 & 24.2 & \\
\hline $2-3$ & 692 & 18.5 & \\
\hline$\geq 4$ & 41 & 12.9 & \\
\hline Type of Visit & & & $<0.0001$ \\
\hline Chronic & 1,543 & 19.8 & \\
\hline Acute/Other & 174 & 20.6 & \\
\hline Time with current $\mathrm{PCP}{ }^{* * *}$ & & 22.9 & 0.303 \\
\hline$<1$ year & 171 & 11.4 & \\
\hline
\end{tabular}

$J$ Am Soc Hypertens. Author manuscript; available in PMC 2011 September 1. 


\begin{tabular}{lccc}
\hline Characteristic & N & Weighted \% & P-Value $^{*}$ \\
\hline 1-2 years & 617 & 14.4 & \\
3-4 years & 295 & 29.2 & \\
25 years & 535 & 33.5 & \\
Prior visits above goal & & 46.0 & \\
0 visits & 612 & & 0.020 \\
1 visit & 460 & 22.1 & \\
$\geq 2$ visits & 645 & 20.7 & \\
PCP Specialty & & & 0.858 \\
General/Family Practice & 856 & 27.4 & \\
Internal Medicine & 668 & 20.6 & \\
Other/Unknown & 193 & 18.4 & \\
\hline
\end{tabular}

FF-adjusted Rao-Scott chi square p-value, unless otherwise noted.

* The systolic or diastolic blood pressure value was missing for 10 visits; therefore, $\mathrm{n}$ for these analyses is 8,228 .

**

Tobacco use among those screened: $n=5,718$. Medication change occurred for $n=1,234$.

For 256 visits, no first visit date of the patient to the current provider was abstracted. Therefore, time period with current provider could not be established. Remaining $n=7,982$. 
Table 6

Adjusted Associations between Patient Characteristics and Documented Change in Anti-Hypertensive Medication(s) During Visits at Which Blood Pressure was Above Goal Over the Course of One Year $\left(\mathrm{n}=8,228^{*}\right)$

\begin{tabular}{|c|c|c|c|}
\hline Characteristic & $\mathbf{N}$ & Odds Ratio & $\begin{array}{r}95 \% \text { Confidence } \\
\text { Interval }\end{array}$ \\
\hline \multicolumn{4}{|l|}{ BP level above goal } \\
\hline$<10 / 5 \mathrm{~mm} \mathrm{Hg}$ & 393 & ref & ref \\
\hline 10-19/5-9 mm Hg & 294 & 1.4 & $1.1-1.8$ \\
\hline 20-29/10-14 mm Hg & 404 & 3.4 & $2.8-4.1$ \\
\hline 30-39/15-19 mm Hg & 192 & 4.6 & $3.6-5.8$ \\
\hline$\geq 40 / 20 \mathrm{~mm} \mathrm{Hg}$ & 432 & 7.9 & $6.2-10.2$ \\
\hline \multicolumn{4}{|l|}{ Sex } \\
\hline Male & 478 & 1.0 & $0.9-1.2$ \\
\hline Female & 1,239 & ref & ref \\
\hline \multicolumn{4}{|l|}{ Age group } \\
\hline 21-39 years & 317 & 1.8 & $1.4-2.2$ \\
\hline 40-64 years & 1,071 & 1.3 & $1.1-1.6$ \\
\hline$\geq 65$ years & 329 & ref & ref \\
\hline \multicolumn{4}{|l|}{ Race group } \\
\hline White & 553 & ref & ref \\
\hline Black & 1,064 & 1.1 & $0.9-1.4$ \\
\hline Other & 100 & 1.3 & $1.0-1.7$ \\
\hline \multicolumn{4}{|l|}{ Obesity } \\
\hline BMI lower than 30.0 & 624 & 1.3 & $0.7-2.5$ \\
\hline Obese & 1,071 & 1.1 & $0.6-2.0$ \\
\hline BMI Unknown & 22 & ref & ref \\
\hline \multicolumn{4}{|l|}{ Diabetes } \\
\hline Yes & 751 & ref & ref \\
\hline No & 966 & 1.9 & $1.6-2.3$ \\
\hline \multicolumn{4}{|c|}{ Multiple chronic conditions } \\
\hline $0-1$ & 984 & ref & ref \\
\hline $2-3$ & 692 & 0.9 & $0.8-1.1$ \\
\hline$\geq 4$ & 41 & 0.6 & $0.4-1.0$ \\
\hline \multicolumn{4}{|l|}{ Prior visits above goal } \\
\hline 0 visits & 612 & ref & ref \\
\hline 1 visit & 460 & 1.0 & $0.8-1.1$ \\
\hline$\geq 2$ visits & 645 & 1.1 & $0.9-1.3$ \\
\hline \multicolumn{4}{|l|}{ Type of Visit } \\
\hline Acute/Other & 174 & ref & ref \\
\hline Chronic & 1,543 & 2.3 & $1.8-3.0$ \\
\hline
\end{tabular}

Number of observations used for this model is 8,228 because BP level above goal was missing for 10 visits. Number of visits with BP level above goal and medication change is 1,715 . ref, referent 